\title{
Cloning and sequence analysis of an actin gene in aloe
}

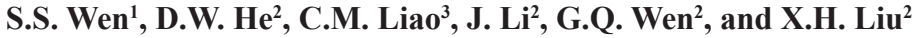 \\ ${ }^{1}$ Rice and Sorghum Research Institute, \\ Sichuan Academy of Agricultural Sciences, Deyang, China \\ ${ }^{2}$ College of Life Science, China West Normal University, Nanchong, China \\ ${ }^{3}$ Library, China West Normal University, Nanchong City, China \\ Corresponding author: G.Q. Wen \\ E-mail: gqin0817@hotmail.com
}

Genet. Mol. Res. 13 (3): 4949-4955 (2014)

Received May 28, 2013

Accepted November 21, 2013

Published July 4, 2014

DOI http://dx.doi.org/10.4238/2014.July.4.9

\begin{abstract}
Aloe (Aloe spp), containing abundant polysaccharides and numerous bioactive ingredients, has remarkable medical, ornamental, calleidic, and edible values. In the present study, the total RNA was extracted from aloe leaf tissue. The isolated high-quality RNA was further used to clone actin gene by using reverse transcriptionpolymerase chain reaction (RT-PCR). The result of sequence analysis for the amplified fragment revealed that the cloned actin gene was 1012 bp in length (GenBank accession No. KC751541.1) and contained a 924-bp coding region and encoded a protein consisting of 307 amino acids. Homologous alignment showed that it shared over 80 and $96 \%$ identity with the nucleotide and amino acid sequences of actin from other plants, respectively. In addition, the cloned gene was used for phylogenetic analyses based on the deduced amino acid sequences, and the results suggested that the actin gene is highly conserved in
\end{abstract}


evolution. The findings of this study will be useful for investigating the expression patterns of other genes in Aloe.

Key words: Aloe (Aloe spp); RNA extraction; Actin gene; Cloning

\section{INTRODUCTION}

Actins are highly conserved proteins in eukaryotic cells. They play a fundamental role in various cellular functions, including cytoskeleton structure maintenance, cell motility, cell division, intracellular movements, contractile processes, and transcription (Zhu et al., 2004; Kozuka et al., 2007; Papakonstanti and Stournaras, 2008). Actins, especially $\beta$-actin, are expressed constitutively and involved in basic housekeeping functions required for cell maintenance (Chang et al., 1998; Calvo et al., 2002). Therefore, they are commonly used as endogenous internal controls for normalizing gene expression studies (Li et al., 2010; Faize et al., 2010). In higher plants, expression and structure of actin genes have been well characterized. For example, in the model terrestrial plant Arabidopsis thaliana, 8 functional actin genes and 2 actin pseudogenes have been reported (McDowel et al., 1996). However, to our knowledge, the study on actin gene in aloe has not yet been reported.

Aloe (Aloe spp), belonging to the family Aloaceae, is a kind of perennial, evergreen, and crassulacean acid metabolism plant. Aloe has many bioactive ingredients such as aloin, aloe emodin, aloe bitter, and aloe lectin (Yao et al., 2007), and the products explored from this species have been widely applied in many fields, including medicine, heath care, cosmetic and food industries (Chang et al., 2007). Thus far, studies on aloe mainly focused on its medicinal components and pharmacological effects, while investigations at molecular level have been considerably limited, especially in gene cloning (Liu et al., 2011). Therefore, in this study, we cloned and analyzed an actin gene from aloe in order to establish an experimental system to be used for gene cloning in aloe.

\section{MATERIAL AND METHODS}

\section{Plant materials}

The mature leaves of aloe Arborescens were collected from our experimental fields and frozen rapidly in liquid nitrogen; subsequently, they were stored at $-20^{\circ} \mathrm{C}$ before RNA extraction.

\section{RNA extraction}

The key reagent used for total RNA extraction was RNAiso Plus (TAKARA Biotechnology Co. Ltd., Dalian, China), and the experimental procedure was referred to the operating manual of the reagent.

The purity and yield of total RNA were determined by monitoring the $\mathrm{A}_{260} / \mathrm{A}_{280}$ absorbance ratio by using NanoDrop 2000 (Thermo Fisher Scientific Inc.). The sample integrality was tested using $1.0 \%$ agarose gel electrophoresis stained with ethidium bromide (EB). 


\section{Reverse transcription polymerase chain reaction}

Reverse transcription polymerase chain reaction (RT-PCR) primers were designed using the software Primer Premier 6.0 according to the mRNA sequence of actin gene of Helianthus annuus (AF282624), Ricinus communis (XM_002530665), Picea rubens (AF172094), Litchi chinensis (HQ615689), Jatropha curcas (HM044307), and Hordeum vulgare (AY145451). The primer sequences used to amplify cDNA are as follows:

Forward primer: 5'-GTGACAATGGAACAGGAATG-3'

Reverse primer: 5'-CACTTCCGGTGGACAATG-3'

Total RNA was synthesized into cDNAs by using a reverse transcription kit (PrimeScript ${ }^{\mathbb{B}}$ One Step RT-PCR Kit Ver.2; TAKARA Biotechnology Co. Ltd., Dalian, China) according to manufacturer instructions. The reaction system $(25 \mu \mathrm{L})$ included $1 \mu \mathrm{L}$ 1-step Enzyme Mix (containing PrimeScript RTase, Ex Taq HS, and RNase inhibitor), $12.5 \mu \mathrm{L} 2 \mathrm{X}$ 1 -step buffer (consisting of reaction buffer, dNTP mixture, and enhance solution), $0.5 \mu \mathrm{L}$ forward primer, $0.5 \mu \mathrm{L}$ reverse primer, $2 \mu \mathrm{L}$ template RNA, and $8.5 \mu \mathrm{L}$ RNase-free $\mathrm{H}_{2} \mathrm{O}$. The reverse transcription reaction was carried out at $50^{\circ} \mathrm{C}$ for $30 \mathrm{~min}$. The amplification procedure was designed as follows: $94^{\circ} \mathrm{C}$ for $2 \mathrm{~min}$, followed by 30 cycles of $94^{\circ} \mathrm{C}$ for $30 \mathrm{~s}, 46^{\circ} \mathrm{C}$ for $30 \mathrm{~s}$, and $72^{\circ} \mathrm{C}$ for $1 \mathrm{~min}$, and a final elongation step of $72^{\circ} \mathrm{C}$ for $7 \mathrm{~min}$. The PCR products were electrophoresed on a $1.0 \%$ agarose gel containing $0.5 \mathrm{mg} / \mathrm{mL}$ EB in TBE buffer and photographed under UV light. Subsequently, the PCR products were purified using DNA gel extraction kit (Sangon Biotech Co. Ltd., Shanghai, China). Finally, the purified products were sequenced by Takara Biotech Co. Ltd. (Dalian, China).

\section{Data analysis}

The sequence of the cloned gene was analyzed by GenScan (http://genes.mit.edu/ GENSCAN.html). Homology search was performed with Blast 2.1 (http://www.ncbi.nlm.nih. gov/blast/). The open reading frame (ORF) of the DNA sequence was searched using ORF finder (http://www.ncbi.nlm.nih.gov/gorf/gorf.html). Protein structure of the AlACT sequence cloned was deduced using the predict protein software (http://www.expasy.ch/tools/scanprosite/). Multiple sequence alignment was performed using DNAMAN6.0. The prediction of protein functional sites and biochemical characteristics were analyzed using the ExPASy Proteomics Server software. The evolutionary tree was constructed using the MEGA 4.0 software.

\section{RESULTS}

\section{Quantity and purity of RNA}

The integrity of the RNA was tested on a $1.0 \%$ agarose gel with $5 \mu \mathrm{L}$ each sample in TBE buffer. A clear RNA band in lane 1 suggested that the extracted RNA had good purity and integrity (Figure 1).

Furthermore, the RNA sample was assessed by spectrophotometry by using $2-\mu \mathrm{L}$ sample to determine the quality and purity. The $\mathrm{A}_{260} / \mathrm{A}_{280}$ absorbance ratio of the extracted RNA was close to 2.0 (Table 1). This result indicated that the RNA isolated by this approach was largely free of contaminating proteins and was in agreement with the result obtained by electrophoresis analysis. 


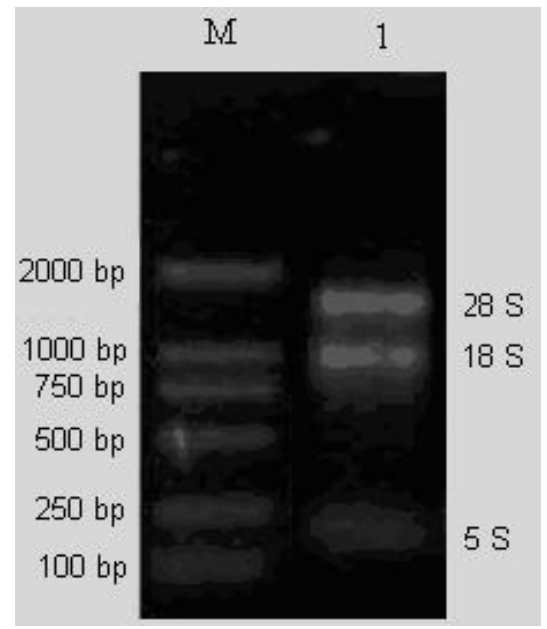

Figure 1. Argarose gel electrophoresis of the extracted total RNA from aloe. Lane $M=$ DNA marker; lane $1=$ total RNA sample.

Table 1. Results by spectrophotometry for the extracted RNA from aloe.

\begin{tabular}{lccc}
\hline $\mathrm{A}_{260}$ & $\mathrm{~A}_{280} / \mathrm{A}_{280}$ & $\mathrm{~A}_{260} / \mathrm{A}_{230}$ & Concentration $(\mathrm{ng} / \mu \mathrm{L})$ \\
\hline 2.75 & 2.08 & 1.30 & 109.9 \\
\hline
\end{tabular}

\section{RT-PCR}

RT-PCR product of actin gene was analyzed using electrophoresis, and about 1000-bplength DNA fragment was amplified using the designed primers (Figure 2). Further sequencing indicated that the length of the cDNA fragment cloned was $1062 \mathrm{bp}$ (Figure 3). This sequence length was remarkably consistent with the electrophoresis result.

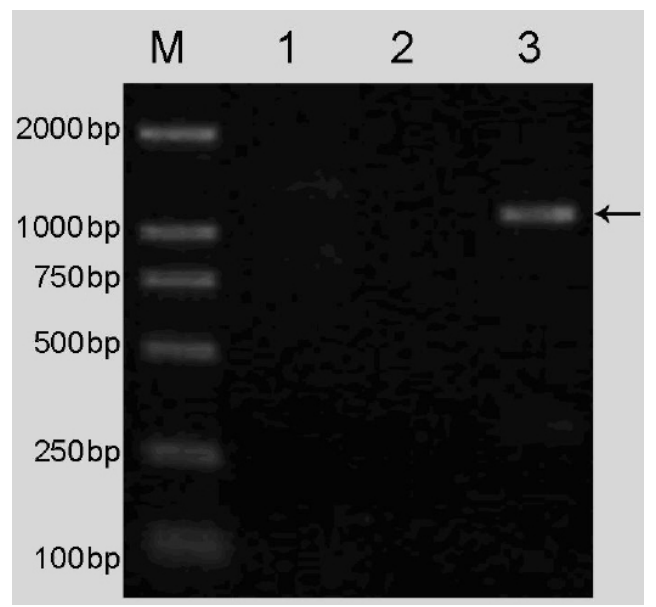

Figure 2. Argarose gel electrophoresis of RT-PCR products of the actin cDNA from aloe. Lane $M=$ DNA marker; lanes 1, 2, and 3 were negative control, $2 \mu \mathrm{L}$ RNA template and RT-PCR product, respectively. 


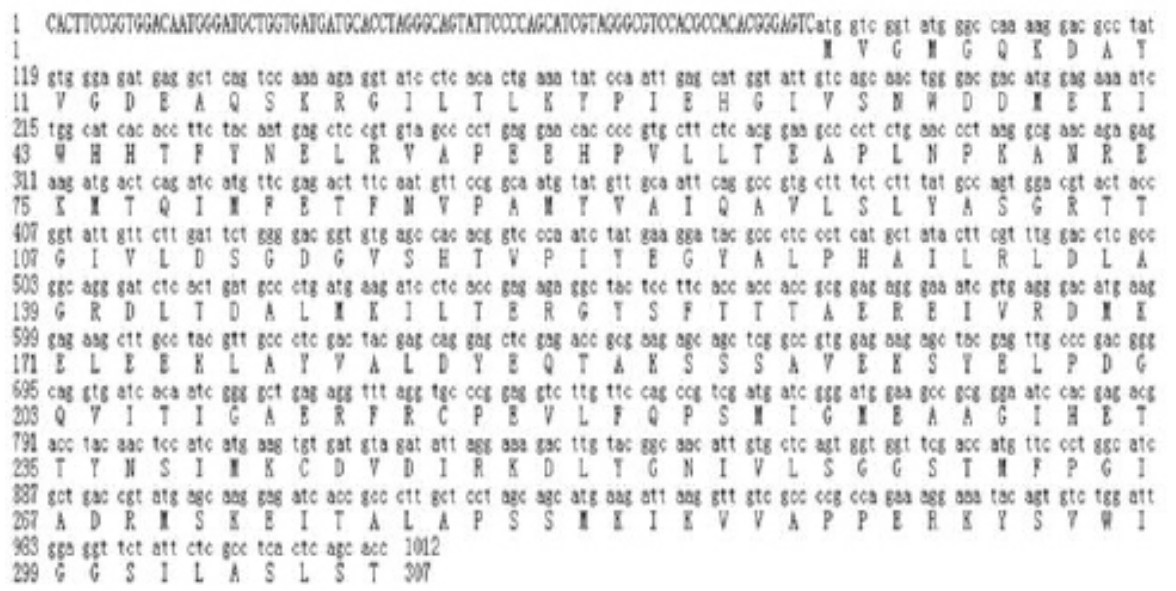

Figure 3. Nucleotide sequence and deduced amino acid sequence of the actin gene from aloe.

\section{Analysis of actin gene homology and phylogenetic tree}

The ORF analysis indicated that the cloned actin gene contains a partial ORF. Blast research analysis revealed that the actin cDNA sequence shares over $80 \%$ nucleotide identity with other NCBI/GenBank data. An identity of approximately $96 \%$ was observed among the sequences of the mature proteins. This also suggested that the clone was indeed actin gene. At present, the gene sequence has been submitted to GenBank (accession No. KC751541.1). The dendrogram constructed based on the amino acid sequences of the coding domains revealed that the actin protein was included in an independent branch (Figure 4). Additionally, the plants belonging to the same family in taxonomy tended to usually cluster together, for instance, Zea mays, Sorghum bicolor, and Hordeum vulgare were included under Gramineae. However, 7 actin genes from Arabidopsis thaliana of Cruciferae were located in different branches. These results suggested that plant actins show certain complexity in genetic evolution, which might probably be related to their different functions.

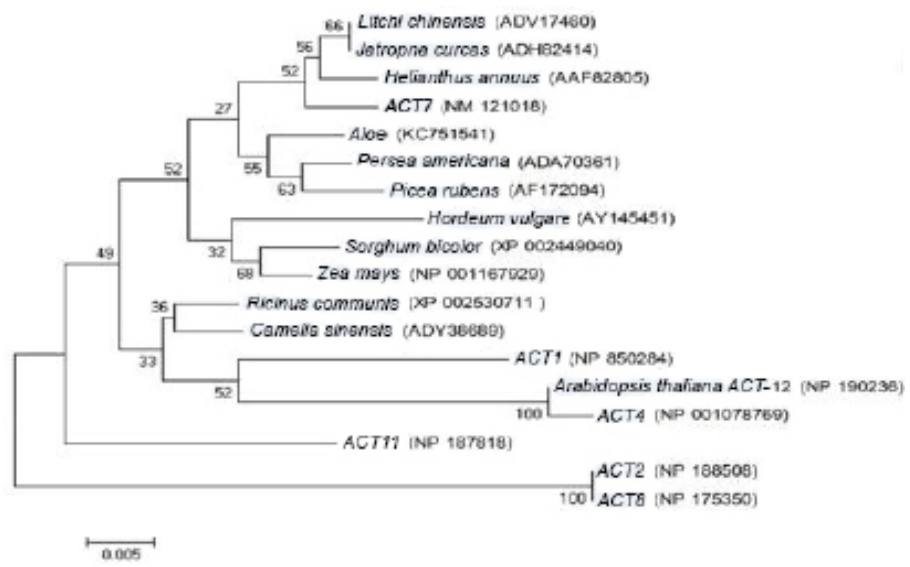

Figure 4. Dendrogram of different species based on amino acid sequence of actin gene. 


\section{DISCUSSION}

Actins are very important structure proteins for organisms. They are found in nearly all eukaryotic cells, and play essential roles in cellular activities. Most actins have 374-377 amino acid residues. The encoded protein sequences are usually highly conserved during biological evolution.

Several studies have found that a closer relationship in taxonomy corresponds to higher similarity in the amino acid sequence. Interestingly, despite the highly conserved protein sequences of actins, vertebrate actin genes exhibit distinct tissue- and stage-specific patterns of expression. In our study, an actin gene fragment (named AlACT) was isolated from aloe by using RT-PCR. Sequence analysis revealed that $A l A C T$ gene has high homology with the nucleotide sequences deposited in GenBank; further, the deduced amino acid sequence was in concordance with that reported previously. The results of multi-sequence alignment of modified sites indicated that the actin protein has a distinct characteristic signal sequence and some conservative phosphorylation sites (Figure 5); in addition, some complex modifications and regulations occur at the protein level. However, no actin signature 2 site was found in the deduced amino acid sequence due to the missing mutations. Boldogh and Pon (2006) studied the interactions between mitochondria and the actin cytoskeleton and found that mutations in actin or actin-binding proteins can influence mitochondrial pathways leading to cell death. In this study, we also found mutations in the actin gene; however, its influence and regulation in function need to be further studied.

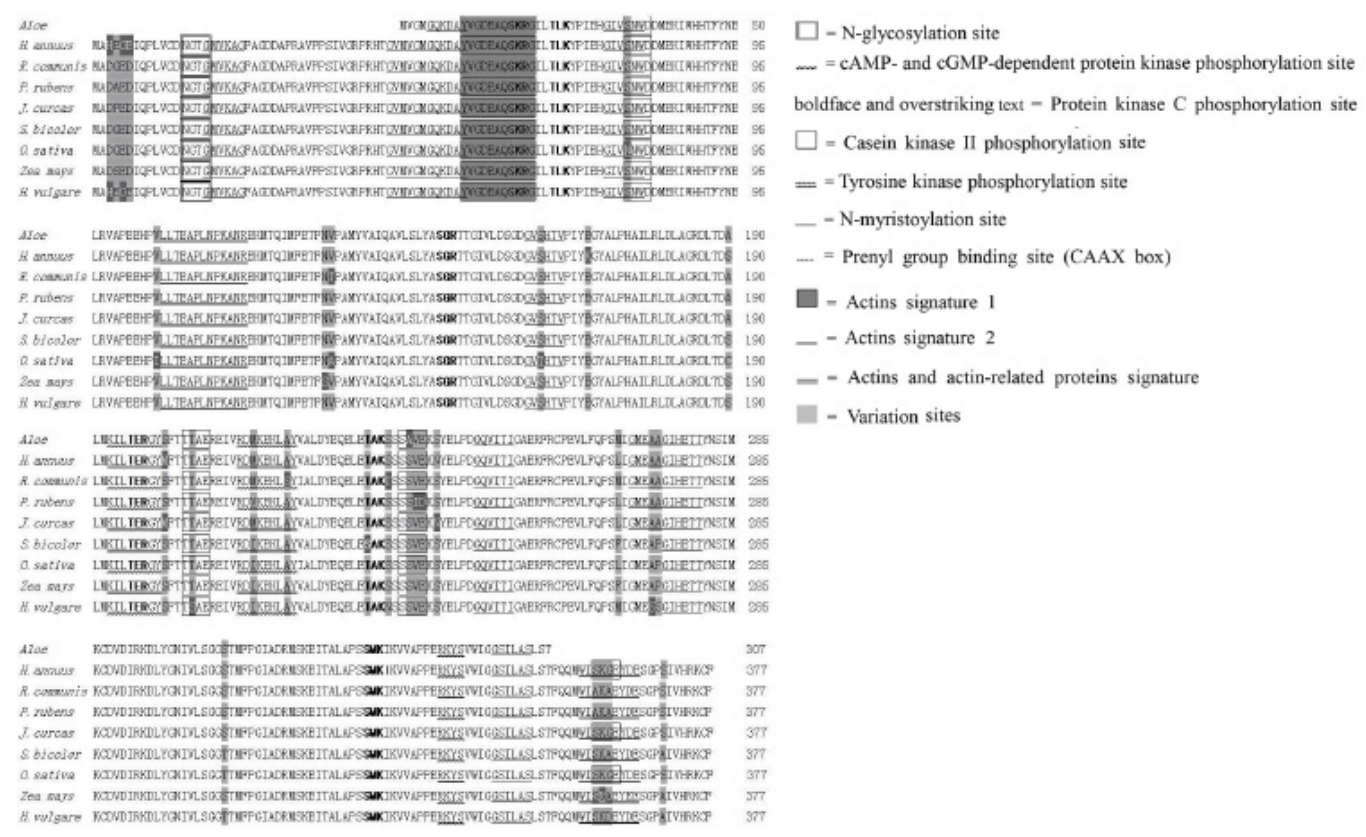

Figure 5. Multi-sequence alignment of the actin protein encoded by the cloned actin gene in aloe and other species.

Actin, especially $\beta$-actin, is commonly used to normalize molecular expression due to its high conservation as an endogenous housekeeping gene. However, Ruan and Lai (2007) showed that $\beta$-actin expression can be changed in response to biochemical stimuli during 
growth and differentiation and in disease states. Therefore, whether the actin gene can be used as an endogenous reference in real-time quantitative research needs to be further confirmed. The results of this study will form a basis for our future studies on the gene expression patterns and biological function of actin.

\section{ACKNOWLEDGMENTS}

Research supported by the Scientific Research Fund of Sichuan Provincial Education Department of China (\#13ZA0012).

\section{REFERENCES}

Boldogh IR and Pon LA (2006). Interactions of mitochondria with the actin cytoskeleton. Biochim. Biophys. Acta 1763: 450-462.

Calvo E, Rubiano C, Vargas A and Wasserman M (2002). Expression of housekeeping genes during the asexual cell cycle of Plasmodium falciparum. Parasitol. Res. 88: 267-271.

Chang XL, Feng YM, Cong LH, Tian KM, et al. (2007). Review update on bioactive functions of aloe. Food Sci. Technol. 5: $10-13$.

Chang TJ, Juan CC, Yin PH, Chi CW, et al. (1998). Up-regulation of beta-actin, cyclophilin and GAPDH in N1S1 rat hepatoma. Oncol. Rep. 5: 469-471.

Faize M, Faize L and Burgos L (2010). Using quantitative real-time PCR to detect chimeras in transgenic tobacco and apricot and to monitor their dissociation. BMC Biotechnol. 10: 53.

Kozuka J, Yokota H, Arai Y, Ishii Y, et al. (2007). Dynamic polymorphism of actin as activation mechanism for cell motility. Biosystems 88: 273-282.

Li Z, Yang L, Wang J, Shi W, et al. (2010). beta-Actin is a useful internal control for tissue-specific gene expression studies using quantitative real-time PCR in the half-smooth tongue sole Cynoglossus semilaevis challenged with LPS or Vibrio anguillarum. Fish Shellfish Immunol. 29: 89-93.

Liu XH, Li J, Zhang YS, Li LH, et al. (2011). Biological research advancement of Aloe. J. Med. Plants Res. 5: 1046-1052.

McDowell JM, Huang S, McKinney EC, An YQ, et al. (1996). Structure and evolution of the actin gene family in Arabidopsis thaliana. Genetics 142: 587-602.

Papakonstanti EA and Stournaras C (2008). Cell responses regulated by early reorganization of actin cytoskeleton. FEBS Lett. 582: 2120-2127.

Ruan W and Lai M (2007). Actin, a reliable marker of internal control? Clin. Chim. Acta 385: 1-5.

Yao LH, He GQ and Chen QH (2007). Research progress on biologically active component of aloe and their functional mechanism. Bull. Sci. Technol. 23: 812-815.

Zhu X, Zeng X, Huang B and Hao S (2004). Actin is closely associated with RNA polymerase II and involved in activation of gene transcription. Biochem. Biophys. Res. Commun. 321: 623-630. 